\title{
Changes of DNA methylation and hydroxymethylation in plant protoplast cultures
}

\author{
Pavla Moricová1, Vladan Ondřej²® ${ }^{\bowtie}$ Božena Navrátilová² and Lenka Luhová1 \\ 1Department of Biochemistry and 2Department of Botany, Faculty of Science, Palacký University, Olomouc, Czech Republic
}

\begin{abstract}
Cytosine methylation patterns in higher eukaryotes are important in gene regulation. Along with 5-methylcytosine $(5-\mathrm{mC})$, a newly discovered constituent of mammalian DNA, 5-hydroxymethylcytosine (5-hmC), is the other modified base in higher organisms. In this study we detected 5-hmC in plant protoplast DNA and demonstrated its increasing content during the first $72 \mathrm{hrs}$. of protoplast cultivation. In contrast to $5-\mathrm{hmC}$, the amount of 5-mC decreased during protoplast cultivation. It was also found that $5-\mathrm{hmC}$ did not primarily arise as a product of oxidative DNA damage following protoplast culture.
\end{abstract}

Key words: protoplasts; DNA methylation; DNA hydroxymethylation; Cucumis sativus; Brassica oleracea

Received: 21 June, 2012; revised: 08 Jnauary, 2013; accepted: 21 February, 2013; available on-line: 15 March, 2013

\section{INTRODUCTION}

The plant protoplast system represents one of the most spectacular examples of cell de-differentiation, which is characterized by large-scale chromatin rearrangement. The fully differentiated, non-dividing mesophyll cells, isolated from donor tissues by cell-wall degrading enzymes are able (upon the application of phytohormones) to proliferate, form calli, and regenerate into plants. During the cells ${ }^{6}$ protoplastization, it is mostly whole heterochromatin (chromocenters) that is transiently de-condensed. Later, new chromocenters are assembled, and a new heterochromatin status is acquired at the time when the protoplast-derived cells re-enter the cell cycle (Ondrej et al., 2009).

Chromatin (the complex of DNA, proteins, and RNA) represents the substrate for most processes in the cell nucleus which involve replication, transcription, as well the maintenance of genome stability and integrity. Moreover, chromatin must retain the ability to make genetic information accessible when needed. This regulation involves levels of chromatin condensation that are connected with epigenetic markers such as DNA methylation and histone modifications (Exner \& Hennig, 2008). The methylation of cytosines $(5-\mathrm{mC})$ in DNA has been found in most eukaryotes, including plants, animals, and fungi. Additionally, it is generally accepted that DNA methylation plays an important role in gene repression. It is now evident that epigenetic modifications, including DNA methylation, regulate heterochromatin level and control, as well as the processes of cell differentiation (Avramova, 2002). It is likely that a cell must establish a new balance between the euchromatin and heterochromatin in order to change its differentiation state, since actively transcribed genes are located within open euchromatin; the silenced, repressed genes are located in the heterochromatin. Terminal cell differentiation involves large-scale chromatin remodelling, which turns most of the open euchromatin into condensed heterochromatin (Grigoryev et al., 2006).

DNA might not be modified by way of cytosine methylation alone. Recent studies have shown a high level of 5-hydroxymethylcytosine (5-hmC) in mammalian embryonic stem cell DNA, as well as in Purkinje cells and the brain (Kriaucionis \& Heintz, 2009). Conversion of $5-\mathrm{mC}$ to $5-\mathrm{hmC}$ is mediated by enzymes of the TET family (Tahiliani et al., 2009) or by oxidative damage (Valinluck et al., 2004). Additionally, 5-hmC significantly inhibits the affinity of the methyl-CpG-binding domain of the MeCP2 protein, which plays a key role in methylation-mediated gene silencing (Valinluck et al., 2004).

We focused on the detection of $5-\mathrm{hmC}$ in plant DNA, and compared global epigenetic changes in DNA methylation and hydroxymethylation during the first 72 hrs. of plant protoplast cultures in two different plant species, Cucumis sativus and Brassica oleracea. The cucumber protoplast cultures were only able to proliferate into calli; in contrast, the B. oleracea protoplast cultureswere able to regenerate into plantlets. The levels of DNA modifications were also compared with both the protoplast viability and ROS production modulated by ascorbic acid, to determine if the $5-\mathrm{hmC}$ originated via the oxidative damage of 5-mC.

\section{MATERIALS AND METHODS}

Protoplast isolation and culture. Protoplasts were isolated from leaves of growing young plants in vitro by standard protocols - B. oleracea, var. botrytis cv. SIRIA according to Navrátilová et al., (1997); and C. sativus cv. MARKETER according to Gajdová et al., (2007). The protoplasts of $B$. oleracea were cultured in B medium (Pelletier et al., 1983), and those of C. sativus in LCM1 medium (Gajdová et al., 2007).

For the DNA isolation, $5 \mathrm{ml}$ of protoplast suspension at a cell density of $1.5 \times 10^{5}$ per $\mathrm{ml}$ was cultured in tissue culture flasks (50 ml volume). For other measurements, $1.5 \mathrm{ml}$ of protoplast suspension at the same density was cultured in Petri dishes $(35 \mathrm{~mm})$. Ascorbic acid was added to the cultures immediately after protoplast isolation (PI) at two concentrations: 50 and $100 \mathrm{mg} / \mathrm{l}$ of culture media. The protoplasts were cultured in an incubator at $25^{\circ} \mathrm{C}$ in the dark.

e-mail: vladan.ondrej@upol.cz

Abbreviations: 5-mC, 5-methylcytosine; 5-hmC, 5-hydroxymethylcytosine; PI, protoplast isolation; ROS, reactive oxygen species. 


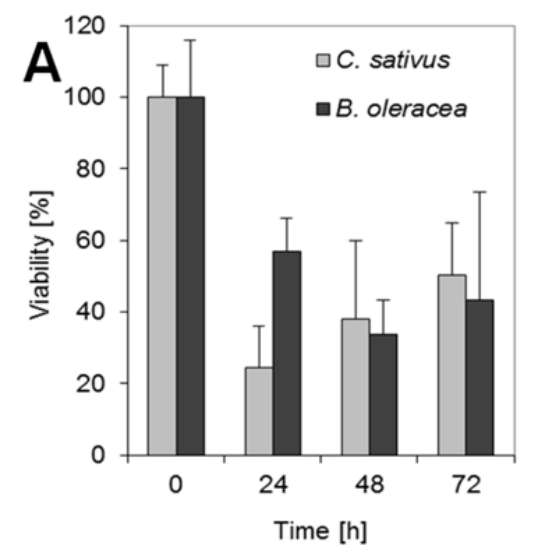

Determination of cell viability by FDA method. Fluorimetric determination of the vitality, using FDA (fluorescein diacetate), was carried out in microplates using a microplate reader (Synergy HT, Biotek, USA). FDA $(5 \mu \mathrm{l}, 25 \mu \mathrm{g} / \mathrm{ml})$ was added to $100 \mu \mathrm{l}$ of cell suspension, and after 10 min of incubation the fluorescence intensity was measured $\left(\lambda_{\text {exc }}-485 \mathrm{~nm}\right.$ and $\left.\lambda_{\mathrm{em}}-515 \mathrm{~nm}\right)$.

ROS measurement. The concentration of $\mathrm{H}_{2} \mathrm{O}_{2}$ in protoplast suspension was determined fluorimetrically using the fluorescent probe 2,7-dichlorodihydrofluorescein diacetate $\left(\mathrm{H}_{2} \mathrm{DCF} \mathrm{DA}\right)$. $\mathrm{H}_{2} \mathrm{DCF}$ DA can permeate through the cell membrane into the cell, where it is metabolised by cell esterases into $\mathrm{H}_{2} \mathrm{DCF}$. Next, the $\mathrm{H}_{2} \mathrm{DCF}$ is oxidized by reactive oxygen species into fluorescent DCF. The $\mathrm{H}_{2} \mathrm{O}_{2}$ assessments were performed on a microplate reader (Synergy HT, Biotek, USA). Five microliters of $0.2 \mathrm{mM} \mathrm{H_{2 }}$ DCF DA fluorescent probe was added into $100 \mu \mathrm{l}$ of cell suspension. The fluorescent signal $\left(\lambda_{\text {exc }}-485 \mathrm{~nm}\right.$ and $\left.\lambda_{\text {em }}-515 \mathrm{~nm}\right)$ was measured immediately after the addition of the probe, as well as after incubation of the cell suspension for 1 hour at $26^{\circ} \mathrm{C}$ in the dark. For each experimental variant, three measurements were conducted for each of the three independent sets of samples (i.e., nine values were obtained). The data are presented as the mean + standard deviation.

DNA methylation and hydroxymethylation level measurement. DNA was isolated from the protoplast cultures at 0, 24, 48 and 72 hrs after protoplast isolation (PI) and from donor leaves by standard CTAB procedure. DNA modifications were quantified using colorimetric assays with MethylFlash Hydroxymethylated and Methylated DNA Quantification Kits (Epigentec, USA) according to the manufacturer's protocols. The relative quantities of 5 -hmC and 5 -mC were calculated according to manufacturer's formulas using the manufacturer's standards.

\section{RESULTS AND DISCUSSION}

Two protoplast culture systems were used to study global epigenetic changes of DNA. The first one, based on $B$. oleracea, is a highly regenerative system that gives a stable high number of regenerated plantlets, which have been used in somatic hybridization (Navrátilová et al., 1997). In the second system, C. sativus, the protoplasts are able to form calli or somatic proembryos; however, no plants have been obtained by this means of culture, no matter how many genotypes and media modifications were used (Gajdová et al., 2007; Ondrej et al., 2009a).
Figure 1. Measurements of viability and ROS production in protoplast cultures during culture period.

Subset A shows dramatic decreasing of viability of protoplasts after their isolation and slight growth of the viability at the end of the culture period for both studied species $-C$. sativus and B. oleracea. Subset B showed increasing of ROS production in C. sativus protoplast cultures during culture period (72 h). In contrast to $C$. sativus, protoplasts of B. oleracea are able to suppress ROS production.

The two protoplast culture systems did not significantly differ in the viability of the protoplasts during the first $72 \mathrm{~h}$ of culture (Fig. 1a), but they did differ in their ROS production (Fig. 1b). Using a ROS-specific probe, an increasing level and higher amounts of ROS were observed during the culture period of $C$. sativus protoplasts compared to $B$. oleracea, which showed a decreasing tendency after protoplast isolation. At $72 \mathrm{~h}$ after PI, the ROS level in the $B$. oleracea protoplasts increased, which is connected with cell division. An addition of ascorbic acid at a concentration of $50 \mathrm{mg} / \mathrm{l}$ to the culture media strongly inhibited ROS production in the B. oleracea and only moderately and transiently in C. sativus (Fig. 2). Ascorbic acid at $100 \mathrm{mg} / 1$ immediately decreased the level of ROS to below the detection level in both plant species. The ROS reduction effect of ascorbic acid in the cucumber protoplast culture was also described in Ondrej et al. (2010).

At the same time points at which the ROS level and viability were measured, the amounts of $5-\mathrm{hmC}$ and 5 - $\mathrm{mC}$ were determined. The amount of $5-\mathrm{mC}$ in the DNA of freshly isolated protoplasts of both species was nearly the same (about 4\% of relative cytosine content), and decreased during the culturing of both types of protoplasts (Fig. 3a, b). At 72 hrs after PI, the content of $5-\mathrm{mC}$ was significantly lower in the cucumber DNA (Fig. 3a) than in the DNA of the B. oleracea protoplasts

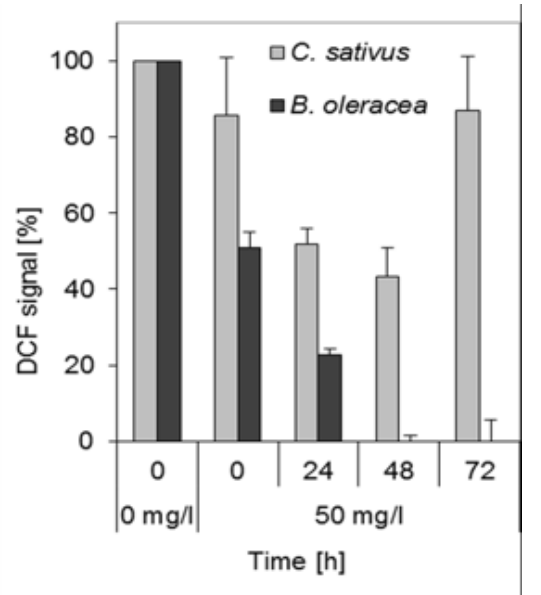

Figure 2. The effect of ascorbic acid addition to culture media on ROS production.

An addition of ascorbic acid at a concentration of $50 \mathrm{mg} / \mathrm{l}$ to the protoplast culture media strongly reduced ROS levels in the $B$. oleracea and only moderately and transiently in C. sativus protoplasts. 

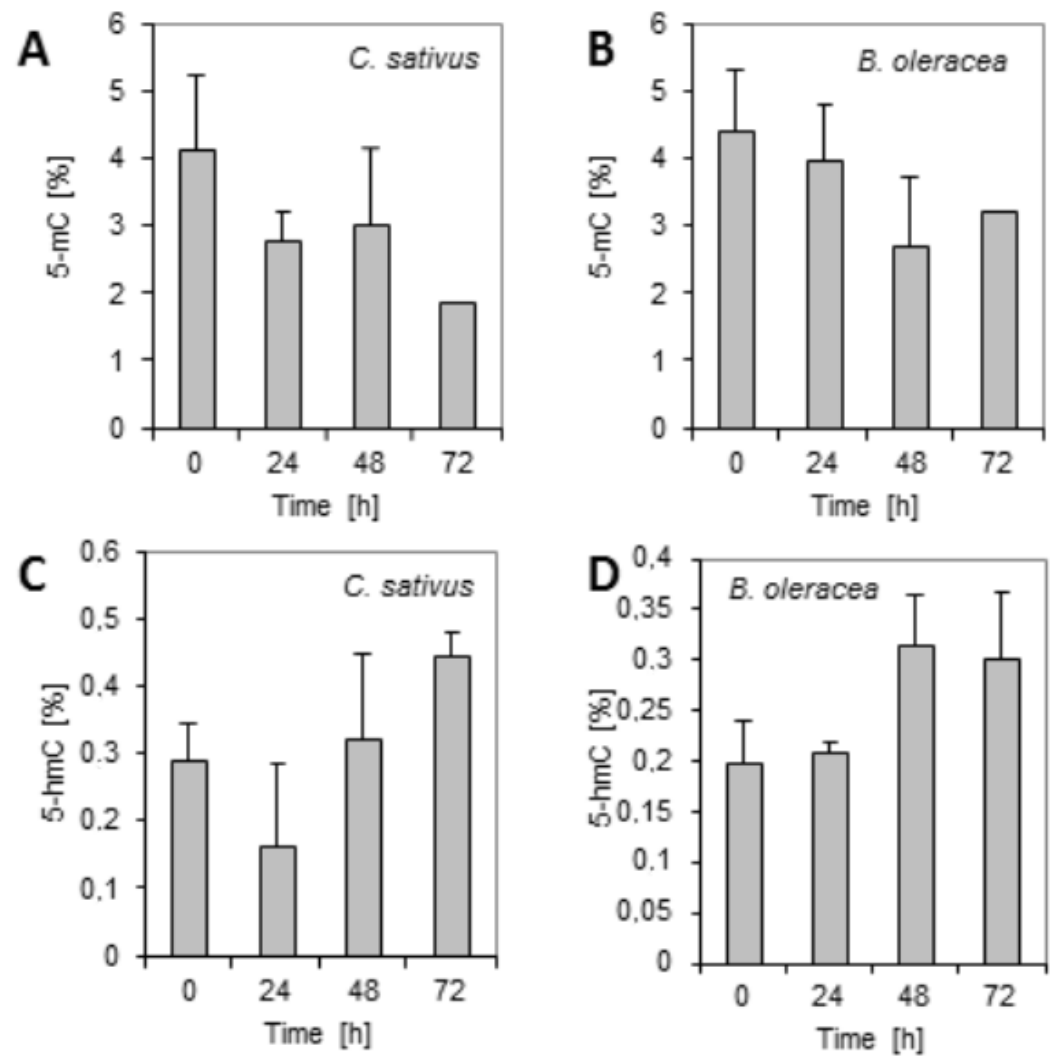

Figure 3. The global changes of 5-mC and 5-hmC content in DNA of protoplast cultures during culturing.

The content of $5-\mathrm{mC}$ (\% of cytosines calculated from standards) in the DNA of freshly isolated protoplasts of both species was nearly the same and decreased during the culturing of both types of protoplasts (A, B). In contrast to 5-mC, the content of 5-hmC has increasing tendency during culturing of $C$. sativus and B. oleracea protoplasts (C, D).
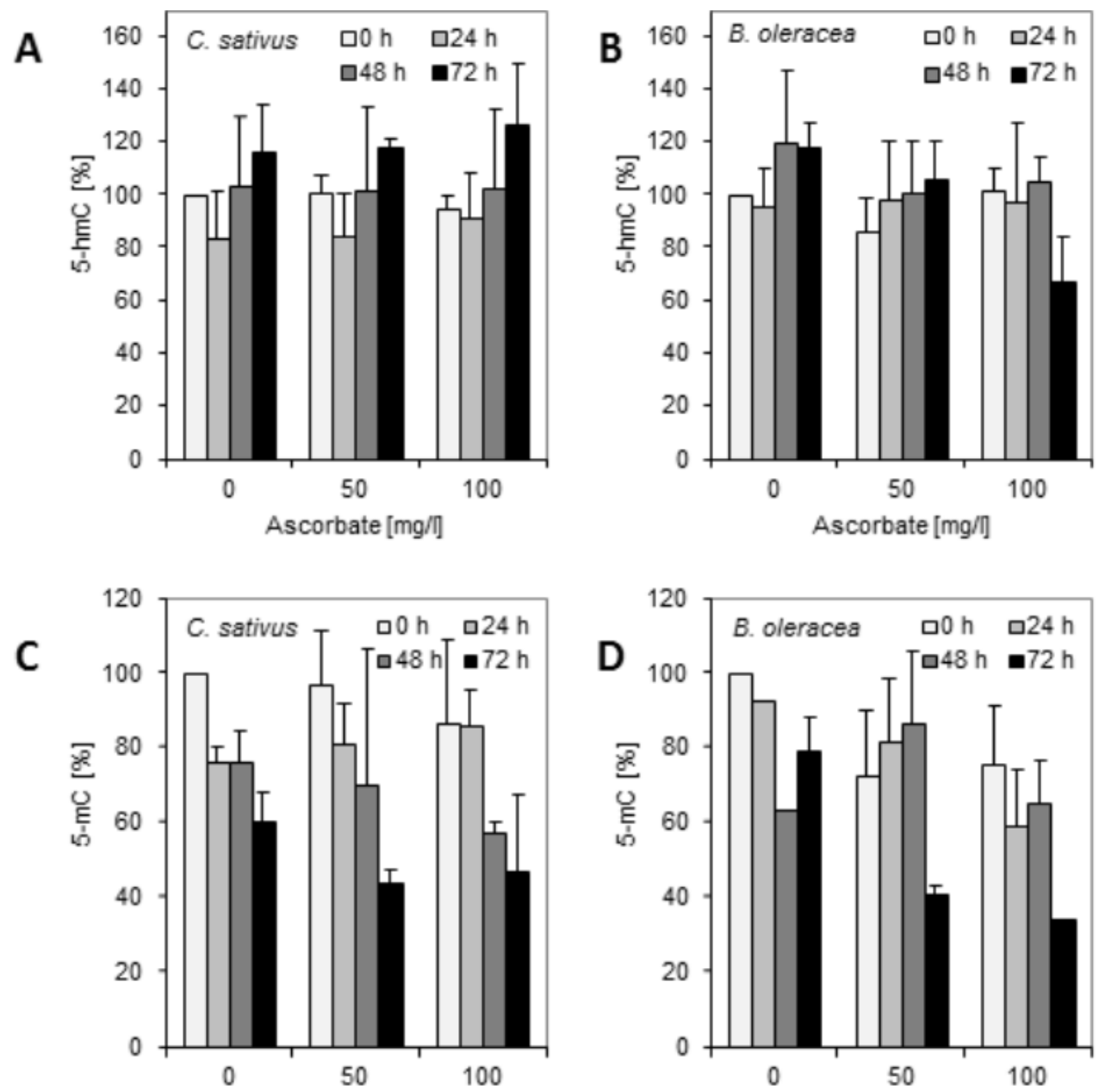

Figure 4. Changes of 5-hmC and 5-mC levels in $C$. sativus and $B$. oleracea protoplast cultures during culturing in the presence of ascorbate.

In comparison to untreated protoplast with ascorbic acid, the treated protoplasts of C. sativus did not show any significant changes in 5-hmC levels (A). But ascorbic acid treated protoplasts of $B$. oleracea displayed a decreasing tendency in 5-hmC level at $72 \mathrm{~h}$ after $\mathrm{PI}$ (B). The 5-mC levels in the protoplast cultures of both studied species treated with ascorbic acid showed a decreasing tendency comparing to untreated cultures (C, D). 
(Fig. 3b). Additionally, the methylation level of DNA in freshly isolated protoplasts did not differ from the methylation levels in leaves that were used for protoplast preparation.

In contrast to $5-\mathrm{mC}$ the amount of $5-\mathrm{hmC}$ displayed an increasing tendency with culture duration in both protoplast systems; and $72 \mathrm{~h} \mathrm{PI}$, the amount of 5 -hmC in cucumber DNA was significantly higher (Fig. 3c) than in the DNA of the B. oleracea protoplasts (Fig. 3d). In the human, Nestor et al. (2012) found that the global 5-hmC content of normal tissues is highly variable, does not correlate with the global 5-mC content, and decreases rapidly as cells from a normal tissue adapt to cell culture.

As mentioned above, the conversion of $5-\mathrm{mC}$ to 5 -hmC is mediated by enzymes from the TET family or by oxidative damage. It is generally accepted that ROS are responsible for DNA damage, and could be responsible for the recalcitrance of plant protoplasts (Papadakis et al., 2002). However, the ROS levels in the cucumber protoplast cultures corresponded with the 5-hmC levels; conversely, the ROS levels in the $B$. oleracea protoplasts decreased during the culture period, but the 5-hmC level increased. We also showed that application of ascorbic acid did not produce significant global changes in DNA hydroxymethylation in the C. sativus cultures. In contrast, the levels of 5 -hmC displayed a decreasing tendency in the $B$. oleracea protoplast cultures at $72 \mathrm{~h}$ after PI when treated with either concentration of ascorbic acid, and no ROS signal was detected (Fig. 4a, b). This shows that the detected changes in DNA hydroxymethylation are mainly independent of DNA damage and are probably due to enzymatic modifications with a small proportion contributed by ROS. The $5-\mathrm{mC}$ level in the protoplast cultures treated with ascorbic acid showed a decreasing tendency comparing to untreated cultures (Fig. 4c, d).

In cucumber protoplasts, 48 and 72 hrs. after PI is the time when heterochromatin blocks (chromocenters) reassemble and the protoplast-derived cells re-enter the cell cycle (Ondrej et al., 2009b; 2010). At those times, we measured the highest levels of $5-\mathrm{hmC}$ and the lowest levels of DNA methylation. As mentioned above (Valinluck et al., 2004), DNA hydroxymethylation decreases the binding affinity of proteins playing a role in heterochromatin formation. The present results reflect, and could be responsible for, the newly reformed and low density heterochromatin status in protoplast nuclei before their first division; additionally, they could also be responsible for the process of cell reprogramming. In humans, mutations in TET genes or their knocking down, which reduce the ability of cells to hydroxymethylate cytosine, lead to pathological differentiation of stem cells and to cancers (Wu \& Zhang, 2011; Tsukada, 2012).

\section{Acknowledgements}

This work was supported by the IGA UP Agency grants $\operatorname{PrF} / 2013 / 003$, and $\operatorname{PrF} / 2011 / 031$.

\section{REFERENCES}

Avramova ZJ (2002) Heterochromatin in animals and plants. Similarities and differencies. Plant Physiol 129: 40-49.

Exner V, Hennig L (2008) Chromatin rearrangements in development. Curr Opin Plant Biol 11: 64-69.

Gajdová J, Navrátilová B, Smolná J, Lebeda A (2007) Factors affecting protoplast isolation and cultivation of Cucumis spp. J Appl Bot Food Qual 81: 1-6.

Grigoryev SA, Bulynko YA, Popova EY (2006) The end adjusts the means: heterochromatin remodeling during terminal cell differentiation. Chromosome Res 14: 53-69.

Kriaucionis S, Heintz, N (2009) The Nuclear DNA Base 5-Hydroxymethylcytosine Is Present in Purkinje Neurons and the Brain. Science 324: 929-930.

Navrátilová B, Bůžek J, Široký J, Havránek P (1997) Construction of intergeneric somatic hybrids between Brassica oleracea and Armoracia rusticana. Biol Plant 39: 531-541.

Nestor CE, Ottaviano R, Reddington J, Sproul D, Reinhardt D, Dunican D, Katz E, Dixon JM, Harrison DJ, Meehan RR (2012) Tissue type is a major modifier of the 5-hydroxymethylcytosine content of human genes. Genome Res 22: 467-477.

Ondrej V, Kitner M, Dolezalova I, Nadvornik P, Navratilova B, Lebeda A (2009b) Chromatin structural rearrangement during dedifferentiation of protoplasts of Cucumis sativus L. Mol Cells 27: 443-447.

Ondrej V, Navratilova B, Lebeda A (2009a) Heterochromatin as a marker for protoplast differentiation of Cucumis sativus. Plant Cell Tiss Org 96: 229-234.

Ondrej V, Navratilova B, Protivankova I, Piterkova J, Sedlarova M, Luhova L, Lebeda A (2010) Recondensation level of repetitive sequences in the plant protoplast nucleus is limited by oxidative stress. J Exp Bot 61: 2395-2401.

Papadakis AK, Roubelakis-Angelakis KA (2002) Oxidative stress could be responsible for the recalcitrance of plant protoplasts. Plant Physiol Biochem 40: 549-559.

Pelletier G, Primard C, Vedel F, Chetrit P, Remy R, Rousselle P, Renard M (1983) Intergeneric cytoplasmic hybridization in Cruciferae by protoplast fusion. Mol Gen Genet 191: 244-250.

Tahiliani M, Koh PK, Shen Y et al. (2009) Conversion of 5-Methylcytosine to 5-Hydroxymethylcytosine in Mammalian DNA by MLL Partner TET1. Science 324: 930-935.

Tsukada Y (2012) Hydroxylation mediates chromatin demethylation. J Biochem 151: 229-246.

Valinluck V, Tsai HH, Rogstad DK et al. (2004) Oxidative damage to methyl-CpG sequences inhibits the binding of the methyl-CpG binding domain (MBD) of methyl-CpG binding protein 2 (MeCP2). Nucl Acids Res 32: 4100-4108.

Wu H, Zhang Y (2011) Mechanisms and functions of Tet protein-mediated 5-methylcytosine oxidation. Genes Dev 25: 2436-2452. 